\title{
Isolated thalamic stroke - analysis of clinical characteristics and asymmetry of lesion distribution in a retrospective cohort study
}

Martin A. Schaller-Paule ${ }^{1 *}$ D, Ariane Martinez Oeckel ${ }^{1}$, Jan-Rüdiger Schüre ${ }^{2,3}$, Fee Keil ${ }^{3}$, Elke Hattingen ${ }^{3}$, Christian Foerch ${ }^{1+}$ and Maximilian Rauch ${ }^{3+}$

\begin{abstract}
Background: More patients with left-hemispheric than right-hemispheric strokes are admitted to hospitals. This is due to the easier recognition of cortical symptoms of the dominant-hemisphere. The thalamus constitutes a "micromodel" of the brain cortex with structure-function relationships known to be asymmetric, especially for language, memory, and visuo-spatial neurocognitive functions. The goal of this study was to characterize clinical symptoms and lesion distribution patterns of patients with acute isolated thalamic stroke (ITS) and to evaluate whether leftsided lesions are overrepresented in the hospital.

Methods: We performed a radiological database search including all brain scans performed in the Center of Neurology and Neurosurgery of the University Hospital Frankfurt between 2010 and 2019. A total of 5733 patients presenting with acute ischemic stroke were screened for ITS. Based on the MRI data, a lesion-overlap map was then generated to visualize the ITS lesion distribution.

Results: Fifty-eight patients with unilateral ITS were identified. A majority of 38 patients (65.5\%) showed left-sided ITS, whereas only 20 patients (34.5\%) had right-sided ITS $(p=0.012)$. A particular difference was found for ITS lesions in the anterior thalamus of the anterolateral $(n=10)$ and anteromedian $(n=3)$ vascular territory, which were located in the left thalamus in $85 \%$ of patients $(p=0.011)$. No distribution difference was found for ITS lesions in the inferomedial $(n=7)$, central $(n=8)$, inferolateral $(n=23)$ and posterior $(n=7)$ vascular territories. The neuropsychological symptoms of thalamic aphasia $(n=8)$, neurocognitive impairment $(n=6)$, behavioral changes $(n=2)$, neglect $(n=2)$ and memory deficits $(n=3)$ were described predominantly in patients with left-sided ITS $(p<$ 0.01). In contrast, other stroke symptoms (e.g., sensorimotor hemi-syndromes) did not reveal a side preponderance.

Conclusions: The better recognizability of left anterior compared to right anterior thalamic stroke symptoms may have an impact on the frequency in which ITS patients are admitted to the hospital. Clinical characteristics of right anterior thalamic stroke should therefore be further investigated, and diagnostic instruments towards their detection be identified.
\end{abstract}

Keywords: Diaschisis, Selection bias, Thalamus, Aphasia, Lateralization, Neuroradiology

\footnotetext{
* Correspondence: martin.schaller@kgu.de

${ }^{+}$Christian Foerch and Maximilian Rauch contributed equally to this work. 'Department of Neurology, University Hospital Frankfurt, Goethe-University,

Schleusenweg 2 - 16, D-60528 Frankfurt am Main, Germany

Full list of author information is available at the end of the article
}

(c) The Author(s). 2021 Open Access This article is licensed under a Creative Commons Attribution 4.0 International License, which permits use, sharing, adaptation, distribution and reproduction in any medium or format, as long as you give appropriate credit to the original author(s) and the source, provide a link to the Creative Commons licence, and indicate if changes were made. The images or other third party material in this article are included in the article's Creative Commons licence, unless indicated otherwise in a credit line to the material. If material is not included in the article's Creative Commons licence and your intended use is not permitted by statutory regulation or exceeds the permitted use, you will need to obtain permission directly from the copyright holder. To view a copy of this licence, visit http://creativecommons.org/licenses/by/4.0/. 


\section{Background}

Left hemispheric strokes are overrepresented in hospitals when compared to right hemispheric strokes $[1,2]$. This is attributed to a selection bias rather than a "true" numeric difference in stroke occurrence. Left hemispheric symptoms such as aphasia, alexia or apraxia can be recognized more easily by patients and next of kin than symptoms associated with the right hemisphere (such as neglect, visuo-spatial deficits or anosognosia). Thalamic strokes present with a wide variety of symptoms depending on their location, volume, and lateralization [3-5]. Numerous studies have already focused on syndromes based on the affected thalamic nuclei and vascular territories. However, it remained undetermined whether the distribution patterns of thalamic strokes admitted to a hospital also reflect leftright differences and are as such a "micro-model" of cortical stroke.

Four vascular territories are commonly defined for isolated thalamic stroke (ITS) [3, 4]. The (1) anterolateral territory is supplied by the tuberothalamic artery from the posterior communicating artery. Paramedian arteries arising from the pre-communicating segment (P1-segment) of the posterior cerebral artery (PCA) supply the (2) inferomedial territory, sporadically originating from an unpaired artery serving both sides [6]. Arising from the post-communicating P2-Segment of PCA, the thalamogeniculate arteries supply the (3) inferolateral territory and the posterior choroidal artery the (4) posterior territory (Table 1) [5, 7]. However, due to frequent variations in vascular supply and individual levels of collateralization the attribution of ITS to specific artery occlusion patterns has proven difficult $[5,8,9]$.

Structure-function relationships in the thalamus are generally asymmetric, an issue already raised in earlier studies on left-right lateralization based on electrical thalamic stimulation at time of stereotaxic operations [4, $10,11]$. It was shown for right handed patients that language processing, memory and neurocognitive functions are commonly mediated by the left anterior thalamus supplied by both or either tuberothalamic and paramedian arteries, while the right anterior thalamus serves as a relay in the prominent processing of visuo-spatial abilities and executive cognitive tasks (e.g. solving a complex maze), spatial awareness (hemi-spatial neglect), facematching, and other non-verbal information processing [10, 12-15]. Consistently, no differences in lateralization were reported for sensory-motor functions (including thalamic pain syndrome), ataxia or hemianopia, as well as tremor and hemichorea, all commonly associated with inferolateral and posterolateral territory [4, 7, 16-18]. Unpaired vascular supply may lead to bilateral paramedian thalamic infarction, which frequently leads to acute vigilance impairment [19].
In summary, a subgroup of thalamic stroke patients may be overlooked in the prehospital setting due to less recognizable symptoms, and hence does not receive due stroke treatment in time. The aim of this study was to analyze the clinical symptoms and left-right lateralization patterns in isolated thalamic stroke patients to identify and further characterize those potentially missed stroke patients.

\section{Methods \\ Study population}

A systematic radiological database search for all thalamic strokes was undertaken for the years 2010 to 2019, scanning a total of 5733 patients presenting with ischemic stroke (ICD10 I 63) in the Center of Neurology and Neurosurgery of the University Hospital Frankfurt (Fig. 1). Cases with clinically and radiologically confirmed diagnosis of ITS only were included, and patients with concurring diagnoses were dismissed. We excluded 45 patients with underlying basilar occlusion and 42 patients with additional acute brain ischemia outside the thalamus (non-isolated thalamic stroke). We identified $62 \mathrm{pa}$ tients with ITS, equaling $1.1 \%$ of all ischemic strokes. Four patients with bithalamic stroke were then excluded from further analysis. Clinical data was gathered and analyzed (M. S-P. and A. M. O.) for the remaining 58 patients with unilateral ITS. During stroke-unit treatment, patients did not undergo specific neuropsychological assessment tests, thus the neurocognitive information provided is based on the treating physicians' clinical findings. In 57 of the patients, MRI data were available, one patient had CT only. First, interdisciplinary agreement on the dimensions of thalamic vascular territories was established based on current literature (Fig. 2). Individual lesion locations were then attributed to the vascular territories by two experienced neuroradiologists (M. R., F. K.) blinded towards the clinical data of the patients and the radiological report. In $29 \%$ (17/58), complete conformity was reached during blinded rating. Incongruent findings were then discussed with a third specialist in neuroradiology (E. H.) and jointly labeled in consensus. Ethical approval for the study was granted by the institutional Review Board of the Ethical Committee at the University Hospital Frankfurt (project-number: 20/616). All research methods were performed in accordance with the relevant guidelines and regulations.

\section{Lesion-overlap heat map}

To address uncertainty caused by interrater variability, we performed a lesion-overlap study in MNI152 standard space to objectively investigate the distribution of 
Table 1 Vascular territories of the thalamus

\begin{tabular}{ll}
\hline Vascular territory and supplying artery & Affected Nuclei $^{*}$ \\
\hline Anterolateral territory & Anterior thalamic nuclei group \\
from tuberothalamic artery & $(A M, A V, A D)$ \\
arising from posterior & ventral amygdalo-fugal pathway \\
communicating artery & ventral IML \\
& intralaminar nuclei $(C L, C M, P f)$ \\
& VA, RN \\
& rostral $V L$, ventral pole of MD
\end{tabular}

\section{mamillothalamic tract}

Anteromedian territory [22]

varying arterial supply

Inferomedial territory

from paramedian artery

arising from pre-communicating

P1-Segment (PCA)

\author{
$M D$ \\ intralaminar nuclei $(\mathrm{CL}, \mathrm{CM}, \mathrm{Pf})$ \\ $\mathrm{IML}$ \\ $M D$ \\ posteromedial VL \\ IML \\ intralaminar nuclei $(C L, C M, P f)$ \\ ventromedial pulvinar and LD
}

mesencephalon (riMLF)

Central territory [22]

varying arterial supply

Inferolateral territory

from thalamogeniculate artery

arising from P2-Segment (PCA)
VPL

intralaminar nuclei $(\mathrm{CL}, \mathrm{CM}, \mathrm{Pf})$

Ventroposterior complex (VPM, $\mathrm{VPL}$, and $\mathrm{VPI})$

$\mathrm{VL}$

MGB

Pulvinar, LD

Lateral: LGB, LD, LP, inferolateral parts of pulvinar, VPL, VL

Medial: MGB, posterior parts of CM and $\mathrm{CL}$, pulvinar
Clinical symptoms $[4,5,8,9,11,12,22,23]$

Neuropsychological deficits:

Decreased arousal, disorientation, mood disorders, personality changes, apathy, executive and drive impairment, perseverative behavior

if left-sided: Thalamic aphasia, verbal short-term and visual memory impairment, amnesic syndrome, acalculia if right-sided: Hemi-spatial neglect, visuo-spatial processing deficits, executive cognitive tasks, non-verbal information processing memory impairment, amnestic syndrome

Hemiparesis, sensory loss, hemiataxia Neuropsychological deficits, memory impairment with severe anterograde amnesia, aphasia, agnosia and neglect, apraxia, executive dysfunction

Acute: Sudden disturbance of vigilance; coma Chronic: "Thalamic dementia" with cognitive deficits, decreased arousal, impaired learning, memory deficits, apraxia, temporal disorientation,

altered personality with apathy, mutism and lethargy, aggression, and agitation

if left-sided: Thalamic aphasia

if right-sided: Visuospatial processing deficits

Motor and/or sensory hemi-syndrome, oculomotor nerve palsy, vertical gaze palsy

Sensory loss, hemiparesis, ataxia

Decreased vigilance, anterograde amnesia, short-term memory impairment

Sensory loss of all modalities, hemiparesis (often transient+), hemiataxia, predominantly on the right: Postlesion thalamic pain syndrome (Déjérine-RoussySyndrome)

Hearing impairment

Behavioral changes

Dystonic posture, ataxic hemiparesis and sensory loss, visual field loss (hemi- or quadrant-anopia), neuropsychological features

Sensory loss, hemiparesis, aphasia, memory

impairment, hand tremor

* vascular supply varies between patients and anatomic conditions, the nuclei principally found in infarction in the given area are stated

$\dagger$ in inferolateral infarction the hemiparesis may be transient due to an edema with affection of the internal capsule

Abbreviations: anteromedial thalamic nucleus (AM), anteroventral thalamic nucleus (AV), anterodorsal thalamic nucleus (AD), intralaminar nuclei of thalamus (INT), ventral anterior thalamic nucleus (VA), ventral lateral thalamic nucleus (VL), medial dorsal thalamic nucleus (MD), internal medullary lamina of thalamus (IML), central lateral thalamic nucleus (CL), centromedian thalamic nucleus $(\mathrm{CM})$, parafascicular thalamic nucleus (Pf), lateral dorsal thalamic nucleus (LD), ventral posterolateral thalamic nucleus (VPL), ventral posteromedial thalamic nucleus (VPM), ventral posterior inferior thalamic nucleus (VPI), lateral posterior thalamic nucleus (LP), medial geniculate thalamic nucleus/body (MGB), lateral geniculate thalamic nucleus/body (LGB), thalamic reticular nucleus (RN), fasciculus longitudinalis medialis (riMLF)

thalamic stroke lesions on both sides. Diffusionweighted (DWI) echo-planar image (EPI) data were aligned via three-dimensional T1-weighted data on the Montreal Neurological Institute MNI152 standard space template ( $1 \mathrm{~mm}$ isotropic resolution). For this purpose, T1-weighted data and DTI data were brain extracted and tissue segmented using the software tools BET and FAST from the FMRIB'S Software Library (FSL, version 5.0.7) toolbox. The DWI $b=0$ data was aligned with the T1-weighted dataset via a boundary-based registration according to the segmented white matter. The T1weighted data set was aligned to the MNI152 template using a combination of linear and non-linear registration. By combining the first (EPI to T1-weighted) and second (T1-weighted to MNI) transformation matrices, the transformation was then applied on the DWI b= 1000 dataset. In total, DWI data of 52 patients were transferred into the MNI152 standard space. Then, ITS infarct masks were manually marked based on DWI in MNI152 standard space and cumulated to generate a lesion heat map, which was projected onto the Oxford thalamic connectivity atlas [20]. Five corrupted MRIdatasets had to be dismissed in the process of data management. 


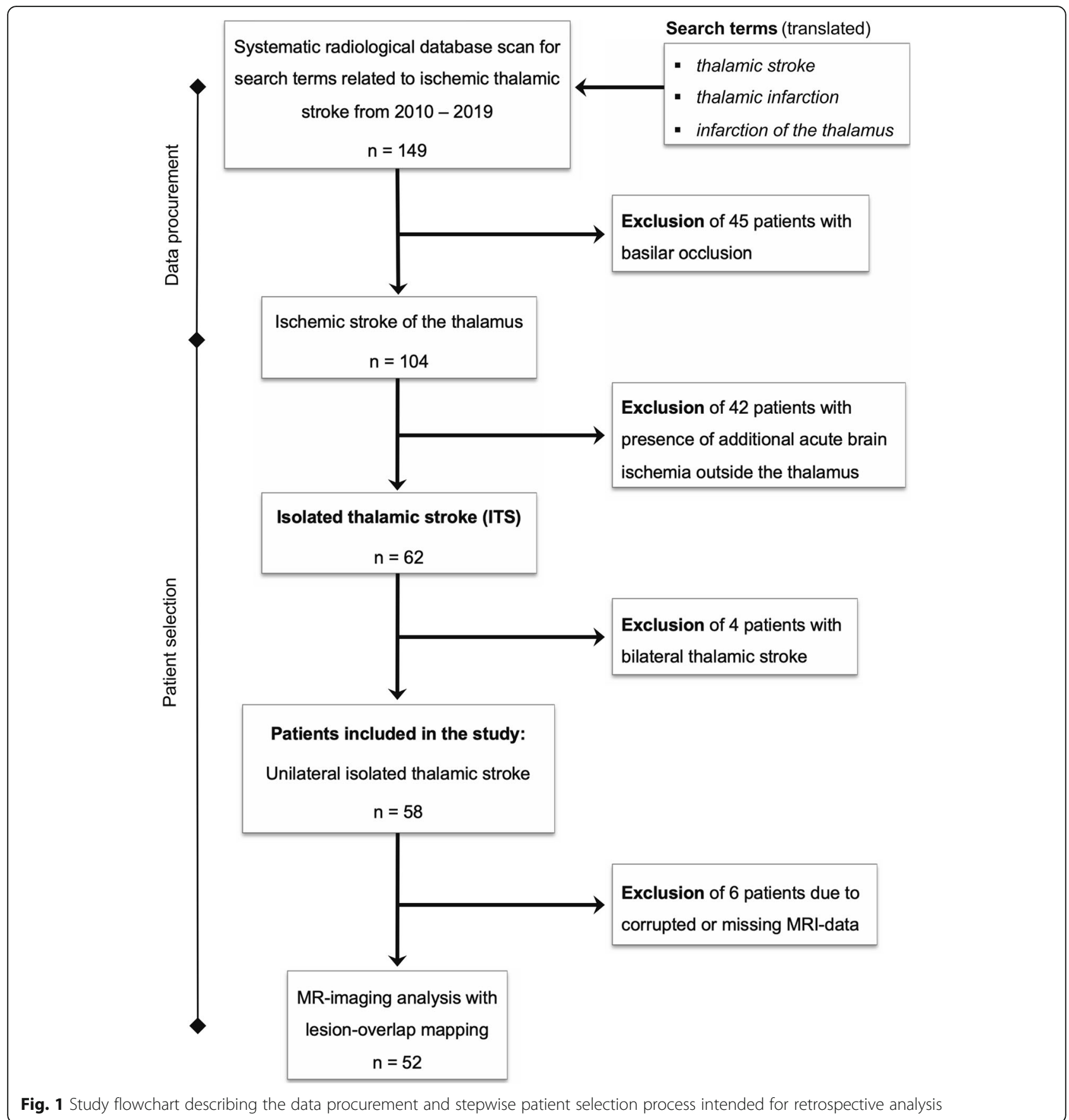

\section{Statistical analysis}

Patient demographics and baseline data were analysed by using summary descriptive statistics. Baseline differences between groups were tested by Welch's twosample t-test for continuous variables, Fisher's exact test for categorial data, and the Mann-Whitney $U$ test was used for non-normally distributed ordinal and continuous variables. Descriptive statistics were used to present baseline characteristics and results of outcome measurements. Differences between the occurrence of left- vs. right-sided lesions were evaluated by the exact binomial test. For all analyses, a level of significance of $p<0.05$ was considered significant. $\mathrm{R}$ in version 3.6.1 was used for statistical calculations.

\section{Results}

A total of 58 patients with ITS were included in the final analysis. Mean age was 62.8 years and $65.5 \%$ of patients were male. The majority of 38 patients showed isolated left-sided ITS (65.5\%), while there were only 20 patients 


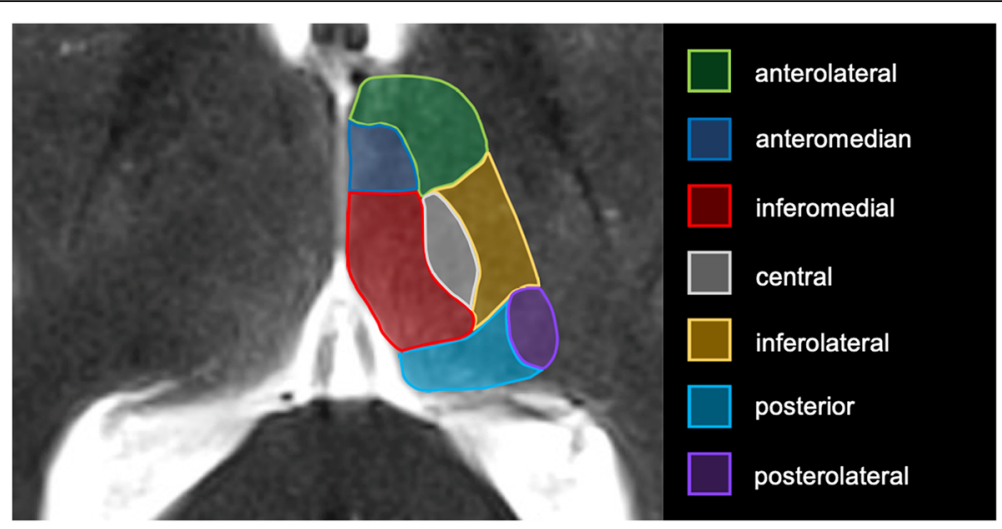

Fig. 2 The thalamic vascular territories as defined in this study projected on an axial T2-weighted MRI template. The map was created based on the literature $[4,7,9,12,22]$ and includes the four traditional and three variant type vascular territories

Table 2 Baseline characteristics

\begin{tabular}{|c|c|c|c|}
\hline Variable & $\begin{array}{l}\text { All ITS } \\
n=58\end{array}$ & $\begin{array}{l}\text { Left ITS } \\
n=38\end{array}$ & $\begin{array}{l}\text { Right ITS } \\
n=20\end{array}$ \\
\hline male sex, No. (\%) & $38(65.5 \%)$ & $25(65.8 \%)$ & $13(65.0 \%)$ \\
\hline age, mean $( \pm$ SD) & $62.8( \pm 15.6)$ & $62.7( \pm 17.2)$ & $62.9( \pm 12.6)$ \\
\hline DWI lesion volume, median (IQR) & $819 \mathrm{~mm}^{3}(531-1235)$ & $923.5 \mathrm{~mm}^{3}(629-1361)$ & $471 \mathrm{~mm}^{3}(268-876)$ \\
\hline within time window $<4.5 \mathrm{~h}$ & $21(36.2 \%)$ & $16(42.1 \%)$ & $5(25.0 \%)$ \\
\hline thrombolysis & $7(12.1 \%)$ & $3(7.9 \%)$ & $4(20.0 \%)$ \\
\hline \multicolumn{4}{|l|}{ THALAMIC TERRITORY } \\
\hline anterolateral & $10(17.2 \%)$ & $8(21.1 \%)$ & $2(10.0 \%)$ \\
\hline anteromedian & $3(5.2 \%$ & $3(7.9 \%)$ & - \\
\hline anterolateral + inferomedial & $1(1.7 \%)$ & $1(2.6 \%)$ & - \\
\hline inferomedial & $6(10.3 \%)$ & $4(10.5 \%)$ & $2(10.0 \%)$ \\
\hline central & $8(13.8 \%)$ & $4(10.5 \%)$ & $4(20.0 \%)$ \\
\hline inferolateral & $23(39.7 \%)$ & $12(31.6 \%)$ & $11(55.0 \%)$ \\
\hline posterolateral & $7(12.1 \%)$ & $6(15.8 \%)$ & $1(5.0 \%)$ \\
\hline \multicolumn{4}{|l|}{ TOAST ETIOLOGY } \\
\hline macroangiopathic & $1(1.7 \%)$ & $1(2.6 \%)$ & - \\
\hline cardio-embolic & $1(1.7 \%)$ & $1(2.6 \%)$ & - \\
\hline microangiopathic & $41(70.7 \%)$ & $26(68.4 \%)$ & $15(75 \%)$ \\
\hline other & $2(3.4 \%)$ & $2(5.3 \%)$ & - \\
\hline undetermined/ESUS & $13(22.4 \%)$ & $8(21.1 \%)$ & $5(25.0 \%)$ \\
\hline \multicolumn{4}{|l|}{ CARDIOVASCULAR RISK FACTORS } \\
\hline hypertension & $44(75.9 \%)$ & $29(76.3 \%)$ & $15(75.0 \%)$ \\
\hline diabetes & $18(31.0 \%)$ & $11(28.9 \%)$ & $7(35.0 \%)$ \\
\hline hypercholesterolemia & $24(41.4 \%)$ & $14(36.8 \%)$ & $10(50 \%)$ \\
\hline atrial fibrillation & $5(8.8 \%)$ & $3(7.9 \%)$ & $2(10.5 \%)$ \\
\hline smoker & $22(37.9 \%)$ & $14(36.8 \%)$ & $8(40 \%)$ \\
\hline microangiopathy on MRI & $29(50.0 \%)$ & $18(47.4 \%)$ & $11(55 \%)$ \\
\hline
\end{tabular}


(34.5\%) with ITS on the right side $(p=0.012)$. No significant differences between sides were found concerning stroke etiology and cardiovascular risk factors (Table 2). Patient admission within the 4.5-h time window $(p=0.16)$ and administration of thrombolysis $(p=0.18)$ did not differ significantly between sides.

Anterolateral and anteromedian territory ITS was found in 11 patients on the left and 2 patients on the right $(p=0.011)$. No significant differences in lateralization were found for central, inferomedial, inferolateral and posterior territory ITS. Thalamic aphasia was described in 8 patients with ITS on the left, but in none of the patients with right-sided ITS $(p<0.01)$. Neuropsychological impairment (vigilance deficits, neurocognitive impairment, behavioral changes, memory deficits, neglect) were apparent in 13 patients with leftsided ITS and in two patients with right-sided ITS ( $p=$ 0.003). In contrast, no lateralization difference was apparent for sensorimotor functions as well as coordinative

Table 3 Clinical characteristics

\begin{tabular}{|c|c|c|c|}
\hline Variable & $\begin{array}{l}\text { All ITS } \\
n=58\end{array}$ & $\begin{array}{l}\text { Left ITS } \\
n=38\end{array}$ & $\begin{array}{l}\text { Right ITS } \\
n=20\end{array}$ \\
\hline GCS on admission (IQR) & $\begin{array}{l}15(15- \\
15)\end{array}$ & $\begin{array}{l}15(15- \\
15)\end{array}$ & $15(15-15)$ \\
\hline NIHSS on admission (IQR) & $2(1-5)$ & $2(1-4.25)$ & $3(1.25-5)$ \\
\hline $\begin{array}{l}\text { NIHSS improvement } \\
\text { on SU (IQR) }{ }^{1}\end{array}$ & $1(0-3)$ & $1(0-2)$ & $\begin{array}{l}1.5(0.25- \\
3.75)\end{array}$ \\
\hline mRS at discharge (IQR) & $0(0-2)$ & $1(0-2)$ & $0(0-1)$ \\
\hline \multicolumn{4}{|c|}{ Neurological findings on admission } \\
\hline vigilance deficits & $4(6.9 \%)$ & 3 & 1 \\
\hline neurocognitive impairment & $6(10.3 \%)$ & 5 & 1 \\
\hline behavioral changes & $2(3.4 \%)$ & 2 & - \\
\hline thalamic aphasia & $8(13.8 \%)$ & 8 & - \\
\hline memory deficits & $3(5.2 \%)$ & 3 & - \\
\hline neglect & $2(3.4 \%)$ & 2 & - \\
\hline visuospatial deficits & none & - & - \\
\hline dysarthria & $15(25.9 \%)$ & 9 & 6 \\
\hline dysphagia & $2(3.4 \%)$ & 1 & 1 \\
\hline hemiparesis & $27(46.6 \%)$ & 16 & 11 \\
\hline sensory loss & $34(58.6 \%)$ & 20 & 14 \\
\hline ataxia & $7(12.1 \%)$ & 6 & 1 \\
\hline vertigo & $5(8.6 \%)$ & 2 & 3 \\
\hline central facial paresis & $8(13.8 \%)$ & 4 & 4 \\
\hline hemianopia & none & - & - \\
\hline oculomotor deficits & $3(5.3 \%)$ & 3 & - \\
\hline thalamic pain syndrome & $2(3.5 \%)$ & 1 & 1 \\
\hline movement disorder & none & - & - \\
\hline
\end{tabular}

Abbreviations: $I Q R=$ interquartile range, $S U=$ stroke-unit.

${ }^{1}$ NIHSS improvement on SU is defined as the difference between NIHSS at admission to the certified stroke-unit and NIHSS at discharge from the stroke-unit and visual symptoms (Table 3). Visuo-spatial deficits were described in none of the patients on either side.

\section{Lesion-overlap map}

A lesion-distribution map was generated using MRI data of 52 patients. As indicated by descriptive data, the leftover-right predominance of ITS can be visualized (Fig. 3). A lesion-overlap heat map focusing on the thalamus clearly illustrates the uneven distribution of strokes in the anterior thalamus with a preponderance on the left. In contrast, the other thalamic territories show a similar stroke frequency, as indicated by color. Based on the individual infarct masks, ITS lesion volumes were analyzed and showed significant larger infarct lesions on the left (median $924 \mathrm{~mm}^{3}$, 95\% CI $879-1407 \mathrm{~mm}^{3}$ ) when compared to right-sided ITS-lesions (median $471 \mathrm{~mm}^{3}, 95 \%$ CI $\left.337-1096 \mathrm{~mm}^{3} ; p<0.001\right)$.

\section{Discussion}

The baseline data of our study cohort were in line with prior clinical studies on ITS, and the analyses met the assumed frequency of ITS patients (62 of 5733 ischemic stroke patients, equaling $1.1 \%)[13,21]$. To our knowledge, this is the first study focusing on the distribution pattern and lateralization of thalamic stroke lesions. If lateralization was specified in prior clinical studies, data frequently revealed a preponderance of left-sided lesions already. However, this was always left undiscussed, as authors chose to rather focus on the thalamic vascular territories [3, 11-13, 21-23]. Other clinical studies even withheld information on lesion lateralization and only differentiated unilateral and bilateral infarction [24]. In the current study, we allocated the ITS lesions into the vascular territories, as previously described in literature, and excluded non-isolated as well as bilateral thalamic strokes $[3-5,21]$. To improve accuracy, we additionally allowed for the description of three distinct variant types (central, anteromedian and posterolateral territory) of thalamic borderzone ischemia [9, 22]. Noteworthy, we encountered a high interrater variability in the process, as vascular supply varies widely between patients, and ITS lesions seldomly fall only into one vascular territory. However, most ITS lesions could ultimately be allocated to one vascular territory in consensus.

This study demonstrated that patients with left-sided thalamic strokes were admitted to the hospital 1.9 times more frequently than patients with right-sided thalamic stroke. The finding correlated with a higher number of patients with ITS lesions in the left anterior thalamus. This asymmetry in anterolateral or anteromedian thalamic vascular territories could also be visualized on the lesion map (Fig. 2). Accordingly, review of clinical symptoms revealed a lateralization pattern for the neuropsychological symptoms thalamic aphasia, memory 


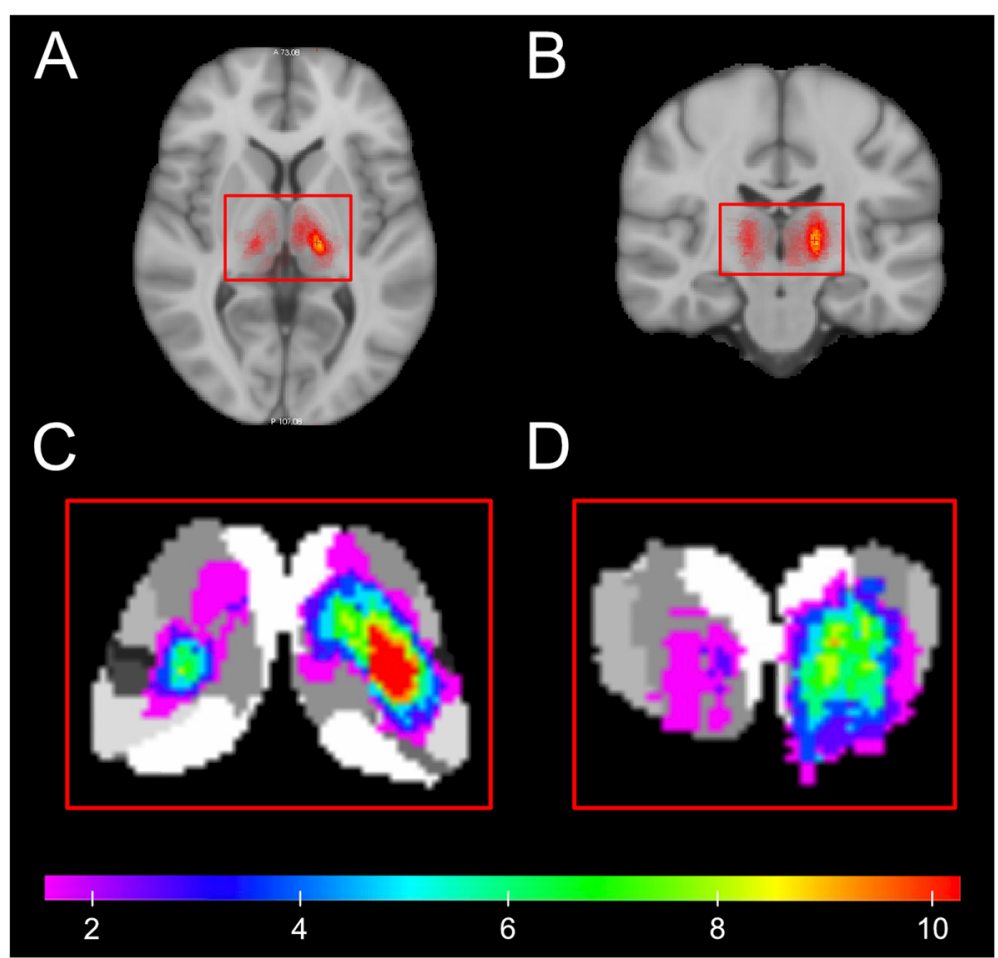

Fig. 3 Lesion-overlap maps in axial and coronal plane of 52 thalamic stroke lesions. Upper row images illustrate the distribution patterns of thalamic strokes in axial (A) and coronal (B) slice in T1-weighted MNI standard space. A higher frequency of infarct lesions in the left thalamus is clearly visible. Lower row images provide a magnified lesion-overlap map of the thalamus in axial (C) and coronal (D) orientation, projected on seven sub-thalamic segments in standard space of the Oxford thalamic connectivity atlas [20]. The lesion distribution pattern as indicated by color visualizes the predominance of left anterior thalamic lesions in the anteromedian and anterolateral vascular territories when compared to right anterior thalamic lesions

deficits, neglect, behavioral changes, and neurocognitive impairment, which were in $95 \%$ ( 20 of 21 patients) associated with left-sided ITS lesions. In contrast, no significant differences were found for lacunar syndromes (e.g., sensorimotor hemi-syndrome), similar to earlier findings for cortical stroke [1]. Therefore, an asymmetry of ITS lesions in the anterior parts of the thalamus most likely drove the predominance of left-sided ITS, and differences in the clinical symptoms may have largely contributed to this phenomenon. Thus, it can be hypothesized that an evenly large group of patients with right anterior ITS exists but was never admitted to the hospital.

To better understand the distribution pattern of this study, contributing factors and potential biases have to be evaluated. The real prevalence of right-sided ITS might be unequally lower in the population, consequently reflecting in the hospital admissions. However, this hypothesis is unlikely, since ischemic strokes were evenly divided in different population-based studies such as the Rotterdam study, and recent large MRI cohorts of lacunar stroke patients showed no side preponderance $[2,25]$. In addition, there is no pathophysiological evidence for an hemodynamic asymmetry of ischemic events between left and right thalamus, as anatomical variations of the posterior circle of Willis such as fetaltype origin of PCA disperse equally [21]. Moreover, the search terms for thalamic stroke were deliberately defined by the study team. But although different search terms could have provided varying numbers of ITS patients, it is implausible that the chosen terms selected one side over the other.

Lastly, the chosen methodology of this study - a retrospective radiological database analysis - could have falsely preselected a specific patient group that is more likely to be admitted to a stroke-unit and receive brain imaging. For example, patients with aphasia may have been selected over patients with other, more subtle symptoms, because the latter might have been considered well treatable in the outpatient sector in advance. Also, primary care providers could have misinterpreted atypical stroke symptoms (e.g., subtle neurocognitive deficits) and attributed the complaints to another nonstroke condition. In addition, right-sided ITS patients themselves might not have presented to the healthcare system at all, because anosognosia is a common symptom of right thalamic lesions [26]. 
In summary, different clinical factors may have considerable impact on whether patients with right anterior ITS get admitted to a stroke-unit. For clarification, the clinical syndrome of right anterior ITS needs to be characterized and distinguished from left-sided ITS symptoms.

In the literature on thalamic functional anatomy, the anterior nucleus of thalamus (ANT) group was described as a key structure for emotional states, executive control, spatial navigation and episodic and visual memory function [27]. In analogy to cortical stroke, a 'lateralized linguistic thalamus' seems evident and recent research has also indicated ample support for a 'lateralized neurocognitive thalamus' $[12,15]$. Univocally, thalamic (transcortical) aphasia and other, higher function language deficits such as retrieval of verbal short-term memory are commonly described in left thalamic lesions $[10,13$, $28,29]$. Further neuropsychological symptoms associated with predominantly left thalamic lesions are constructional apraxia, agnosia, acalculia, behavioral alterations as well as dense amnesic syndrome, especially if the mamillothalamic tract is affected [11]. In contrast, research has indicated a right thalamic predominance for visual neglect, anosognosia, visual memory disturbances, simple speeded processing, mood regulation (depression, euphory, mania) and executive functions [9, 11, 23, 26]. However, literature is still inconsistent in the allocation of symptoms depending on lateralization, sometimes even contradictory $[4,11,15]$. Remarkably, the two patients in this study with right anterior thalamic stroke both showed only a lacunar (motor and sensorimotor) hemi-syndrome and dysarthria with a rapid recovery.

In this study, the lesion volume of right-sided ITS was smaller compared to left-sided ITS. This might be explained by the higher number of anterior ITS lesions on the left, that often spread wider and more extensive into the anterolateral and anteromedian territories. In contrast, right-sided ITS lesions consisted largely (75\%) of small, strategic defects in sensorimotor pathways of the smaller central and inferolateral vascular territories, while only $42 \%$ of left-sided ITS patients had lesions in these locations (Table 2).

The thalamic stroke is a clinical chameleon with a wide range of symptoms far beyond the speech and sensorimotor systems. The clinical presentations of ITS in this study demonstrated that also sudden onset of a neuropsychological deficit is an indicator of thalamic stroke and should be valued accordingly. Though the clinical symptoms of right anterior thalamic stroke remain undetermined, review of literature suggests a syndrome consisting of subtle deficits in visuo-spatial navigation, visual memory impairment, memory function or emotional aspects. Widely used prehospital stroke screening tools such as FAST (Face, Arms, Speech: Time to call Emergency Medical Services) or NIHSS were created to be time-effective and therefore lack the ability to reliably detect neurocognitive deficits. Thus, patients with right-sided anterior thalamic stroke might not be identified and not receive optimized medical care within due time [30]. Even though less apparent neurological symptoms may not greatly affect patients' everyday life, early detection of "silent strokes" is a crucial prerequisite for the timely initiation of secondary prevention in a significantly ageing population of stroke patients [31]. Examination techniques aimed to identify patients with right anterior ITS should therefore be tested in the prehospital sector, especially by primary care providers such as general practitioners and emergency personnel. A decrease of visuo-spatial ability or a hemi-spatial neglect could for example be handily assessed by mental screening tests such as Montréal Cognitive Assessment (MOCA) or Mini-Mental-State-Examination (MMSE). Both are widely available and could be used, if the onset of a neurocognitive deficit is acute or subacute, and help select patients for brain imaging. Since the neuropsychological symptoms of right anterior ITS may be hard to grasp, a low-threshold consultation of the in-house neuropsychologist may also be advisable. Future research should investigate examination techniques to identify right anterior ITS patients and measure their mental performances in neuropsychological test systems.

The number of potentially overlooked patients with right-sided ITS can be extrapolated. The German nationwide administrative database reported 227,542 acute ischemic strokes for the year 2017 alone [32]. With an assumed $1.1 \%$ rate of ITS among all reported strokes $(n=2503)$ and the inequality observed in this study of $65.5 \%$ left-sided and $34.5 \%$ right-sided ITS, approximately $n=777$ right ITS patients may be overlooked every year in Germany.

Primary limitation of this study is the small sample size, that bears considerable risk of a sampling error. Though we identified no systematic methodological errors leading to the observed difference between sides, due to the small number of ITS patients, also minor biases in the patient selection process may have been impactful. However, this clinical study comprised 58 patients within a 10-year recruitment period in a tertiary care center and is amongst the largest clinical ITS patient samples in literature. Since ITS is not a common disease, recruiting considerable higher patient numbers for more reliable statistics is a major technical and organizational obstacle. Therefore, future studies assessing the ITS frequency should chose a multicenter design or use data from a state-wide registry. Furthermore, future population-based MR-studies with analysis of thalamic stroke patterns can provide more definitive insight into lesion distribution patterns. Noteworthy, a systematic neuropsychological testing did not take place in this study and we were dependent on 
information provided by the stroke physicians. For example, although visuo-spatial deficits or movement disorders were not described in this study, they may have stayed undetected due to a lack of neuropsychological testing. Noteworthy, a cumulative overlay of all larger lesions in the center of the thalamus on both sides should be considered when interpreting the lesion-overlap map.

\section{Conclusions}

In summary, more recognizable symptoms of left anterior compared to right anterior ITS may have an impact on the frequency in which thalamic stroke patients are admitted to the hospital. In an unknown number of patients with right anterior ITS, the diagnosis of stroke might be overlooked by available screening methods, hindering patients from receiving medical treatment and secondary prophylaxis in time. This study demands for research aimed at characterizing clinical features of right anterior thalamus infarction, and identifying clinical instruments towards their diagnosis.

\section{Abbreviations}

ANT: anterior nucleus of thalamus; EPI: echo-planar image; ITS: isolated thalamic stroke; MNI: Montreal National Institute; MRS: modified Rankin scale; NIHSS: National Institutes of Health Stroke Scale; PCA: posterior cerebral artery

\section{Acknowledgements \\ We would like to thank Felix Wicke for statistical and epidemiological counseling.}

\section{Authors' contributions}

MSP conceived the study and gained ethical approval. MSP, AMO and CF were involved in study development, literature research and data analysis. MR, EH and FK analyzed and sorted imaging data. JRS and MR were involved in image data processing and image development. MSP wrote the first draft of the manuscript. All authors reviewed and edited the manuscript and approved the final version of the manuscript.

\section{Funding}

There were no sources of research support relevant to the manuscript.

\section{Availability of data and materials}

Data and materials used in this study are available from the corresponding author upon reasonable request.

\section{Declarations}

\section{Ethical approval and consent to participate}

Ethical approval for the study was granted by the institutional Review Board of the Ethical Committee at the University Hospital Frankfurt (REC number: 20/616). Informed written consent was not required for this study.

\section{Consent for publication}

not applicable.

\section{Competing interests}

The Authors declare that there is no conflict of interest.

\section{Author details}

'Department of Neurology, University Hospital Frankfurt, Goethe-University, Schleusenweg 2 - 16, D-60528 Frankfurt am Main, Germany. ${ }^{2}$ Brain Imaging Center, Goethe-University, Frankfurt am Main, Germany. ${ }^{3}$ Institute of Neuroradiology, University Hospital Frankfurt, Goethe-University, Frankfurt am Main, Germany.
Received: 11 June 2021 Accepted: 2 August 2021

Published online: 13 September 2021

\section{References}

1. Foerch, C., Misselwitz, B., Sitzer, M., Berger, K., Steinmetz, H., \& NeumannHaefelin, T. (2005). Difference in recognition of right and left hemispheric stroke. The Lancet., 366(9483), 392-393. https://doi.org/10.1016/s0140-673 6(05)67024-9.

2. Portegies, M. L., Selwaness, M., Hofman, A., Koudstaal, P. J., Vernooij, M. W., \& Ikram, M. A. (2015). Left-sided strokes are more often recognized than rightsided strokes: The Rotterdam study. Stroke., 46(1), 252-254. https://doi.org/1 0.1161/STROKEAHA.114.007385

3. Bogousslavsky, J., Regli, F., \& Uske, A. (1988). Thalamic infarcts: Clinical syndromes, etiology, and prognosis. Neurology., 38(6), 837-848. https://doi. org/10.1212/wnl.38.6.837.

4. Schmahmann, J. D. (2003). Vascular syndromes of the thalamus. Stroke., 34(9), 2264-2278. https://doi.org/10.1161/01.Str.0000087786.38997.9e.

5. Weidauer, S., Nichtweiss, M., Zanella, F. E., \& Lanfermann, H. (2004). Assessment of paramedian thalamic infarcts: MR imaging, clinical features and prognosis. European Radiology., 14(9), 1615-1626. https://doi.org/10.1 007/s00330-004-2303-7.

6. Castaigne, P., Lhermitte, F., Buge, A., Escourolle, R., Hauw, J. J., \& Lyon-Caen, O. (1981). Paramedian thalamic and midbrain infarct: Clinical and neuropathological study. Annals of Neurology, 10(2), 127-148. https://doi. org/10.1002/ana.410100204.

7. Song, Y.-M. (2011). Topographic patterns of thalamic infarcts in association with stroke syndromes and aetiologies. Journal of Neurology, Neurosurgery \& Psychiatry., 82(10), 1083-1086. https://doi.org/10.1136/jnnp.2010.239624.

8. Ghika-Schmid, F., \& Bogousslavsky, J. (2000). The acute behavioral syndrome of anterior thalamic infarction: A prospective study of 12 cases. Annals of Neurology, 48(2), 220-227. https://doi.org/10.1002/1531-8249(200008)48:2<22 0:Aid-ana12>3.0.Co;2-m.

9. Li, S., Kumar, Y., Gupta, N., Abdelbaki, A., Sahwney, H., Kumar, A., ... Mangla, R. (2018). Clinical and neuroimaging findings in thalamic territory infarctions: A review. Journal of Neuroimaging: Official Journal of the American Society of Neuroimaging., 28(4), 343-349. https://doi.org/10.1111/jon.12503.

10. Ojemann, G. A. (1977). Asymmetric function of the thalamus in man. Annals of the New York Academy of Sciences., 299(1 Evolution and), 380-396. https:// doi.org/10.1111/j.1749-6632.1977.tb41923.x.

11. Ld, W., Brouns, R., Kavadias, D., Engelborghs, S., PPd, D., \& Mariën, P. (2011) Cognitive, affective and behavioural disturbances following vascular thalamic lesions: a review. Cortex; a journal devoted to the study of the nervous system and behavior, 47(3), 273-319. https://doi.org/10.1016/j. cortex.2010.09.002

12. Bogousslavsky, J., Regli, F., \& Assal, G. (1986). The syndrome of unilateral tuberothalamic artery territory infarction. Stroke., 17(3), 434-441. https://doi. org/10.1161/01.str.17.3.434.

13. Fritsch, M., Krause, T., Klostermann, F., Villringer, K., Ihrke, M., \& Nolte, C. H. (2020). "Thalamic aphasia" after stroke is associated with left anterior lesion location. Journal of Neurology, 267(1), 106-112. https://doi.org/10.1007/s0041 5-019-09560-1.

14. Ortique, S., Viaud-Delmon, I., Annoni, J. M., Landis, T., Michel, C., Blanke, O., et al. (2001). Pure representational neglect after right thalamic lesion. Annals of Neurology, 50(3), 401-404. https://doi.org/10.1002/ana.1139.

15. van der Werf, Y. D., Weerts, J. G., Jolles, J., Witter, M. P., Lindeboom, J., \& Scheltens, P. (1999). Neuropsychological correlates of a right unilateral lacunar thalamic infarction. Journal of Neurology, Neurosurgery \& Psychiatry., 66(1), 36-42. https://doi.org/10.1136/jnnp.66.1.36.

16. Carrera, E., \& Bogousslavsky, J. (2006). The thalamus and behavior: Effects of anatomically distinct strokes. Neurology., 66(12), 1817-1823. https://doi.org/1 0.1212/01.wnl.0000219679.95223.4c.

17. Guédon, A., Thiebaut, J.-B., Benichi, S., Mikol, J., Moxham, B., \& Plaisant, O. (2019). Dejerine-Roussy syndrome: Historical cases. Neurology., 93(14), 624629. https://doi.org/10.1212/wnl.0000000000008209.

18. Gupta, N., \& Pandey, S. (2018). Post-thalamic stroke movement disorders: A systematic review. European Neurology, 79(5-6), 303-314. https://doi.org/1 $0.1159 / 000490070$.

19. Fritsch, M., Villringer, K., Ganeshan, R., Rangus, I., \& Nolte, C. H. (2021). Frequency, clinical presentation and outcome of vigilance impairment in patients with uni- and bilateral ischemic infarction of the paramedian thalamus. Journal of Neurology. https://doi.org/10.1007/s00415-021-10565-y. 
20. Behrens, T. E. J., Johansen-Berg, H., Woolrich, M. W., Smith, S. M., WheelerKingshott, C. A. M., Boulby, P. A., ... Matthews, P. M. (2003). Non-invasive mapping of connections between human thalamus and cortex using diffusion imaging. Nature Neuroscience., 6(7), 750-757. https://doi.org/10.103 8/nn1075.

21. Goerlitz, J., Wenz, H., Al-Zghloul, M., Kerl, H. U., Groden, C., \& Förster, A. (2015). Anatomical variations in the posterior circle of Willis and Vascular pathologies in isolated unilateral thalamic infarction. Journal of Neuroimaging: Official Journal of the American Society of Neuroimaging., 25(6), 983-988. https://doi.org/10.1111/jon.12235.

22. Carrera, E., Michel, P., \& Bogousslavsky, J. (2004). Anteromedian, central, and posterolateral infarcts of the thalamus: Three variant types. Stroke., 35(12), 2826-2831. https://doi.org/10.1161/01.STR.0000147039.49252.2f.

23. van der Werf, Y. D., Scheltens, P., Lindeboom, J., Witter, M. P., Uylings, H. B. M., \& Jolles, J. (2003). Deficits of memory, executive functioning and attention following infarction in the thalamus; a study of 22 cases with localised lesions. Neuropsychologia., 41(10), 1330-1344. https://doi.org/10.101 6/50028-3932(03)00059-9

24. Kumral, E., Evyapan, D., \& Kutluhan, S. (2000). Pure thalamic infarctions: Clinical findings. Journal of Stroke and Cerebrovascular Diseases., 9(6), 287297. https://doi.org/10.1053/jscd.2000.18741.

25. Barow, E., Pinnschmidt, H., Boutitie, F., Konigsberg, A., Ebinger, M., Endres, M., et al. (2020). Symptoms and probabilistic anatomical mapping of lacunar infarcts. Neurological Research and Practice, 2(1), 21. https://doi.org/10.1186/ s42466-020-00068-y

26. Karussis, D., Leker, R. R., \& Abramsky, O. (2000). Cognitive dysfunction following thalamic stroke: A study of 16 cases and review of the literature. Journal of the Neurological Sciences, 172(1), 25-29. https://doi.org/10.1016/ s0022-510x(99)00267-1.

27. Child, N. D., \& Benarroch, E. E. (2013). Anterior nucleus of the thalamus: Functional organization and clinical implications. Neurology., 81(21), 18691876. https://doi.org/10.1212/01.wnl.0000436078.95856.56.

28. Rangus, I., Fritsch, M., Endres, M., Udke, B., \& Nolte, C. H. (2021). Frequency and phenotype of thalamic aphasia. Journal of Neurology. https://doi.org/1 0.1007/s00415-021-10640-4

29. de Ld, W., Verhoeven, J., Engelborghs, S., PPd, D., \& Mariën, P. (2008). Crossed aphasia and visuo-spatial neglect following a right thalamic stroke: a case study and review of the literature. Behavioural Neurology, 19(4), 177194. https://doi.org/10.1155/2008/905187.

30. Mellor, R. M., Bailey, S., Sheppard, J., Carr, P., Quinn, T., Boyal, A., et al. (2015). Decisions and delays within stroke patients' route to the hospital: a qualitative study. Annals of Emergency Medicine, 65(3), 279-87 e3. https://doi. org/10.1016/j.annemergmed.2014.10.018.

31. Grefkes, C., \& Fink, G. R. (2020). Recovery from stroke: Current concepts and future perspectives. Neurological Research and Practice, 2(1), 17. https://doi. org/10.1186/s42466-020-00060-6.

32. Eyding, J., Bartig, D., Weber, R., Katsanos, A. H., Weimar, C., Hacke, W., \& Krogias, C. (2019). Inpatient TIA and stroke care in adult patients in Germany - retrospective analysis of nationwide administrative data sets of 2011 to 2017. Neurological Research and Practice, 1(1), 39. https://doi.org/10.1186/ s42466-019-0044-y.

\section{Publisher's Note}

Springer Nature remains neutral with regard to jurisdictional claims in published maps and institutional affiliations.

Ready to submit your research? Choose BMC and benefit from:

- fast, convenient online submission

- thorough peer review by experienced researchers in your field

- rapid publication on acceptance

- support for research data, including large and complex data types

- gold Open Access which fosters wider collaboration and increased citations

- maximum visibility for your research: over $100 \mathrm{M}$ website views per year

At BMC, research is always in progress.

Learn more biomedcentral.com/submissions 